\title{
O RECONHECIMENTO NO TRABALHO DE MOTORISTAS DE TRANSPORTE COLETIVO URBANO
}

\author{
THE RECOGNITION IN THE WORK OF URBAN COLLECTIVE TRANSPORT \\ CONDUCTORS
}

J. GONÇALVES ${ }^{*}$, S. DA R. TOLFO ${ }^{1}$ e L. SCHWEITZER ${ }^{1}$

${ }^{1}$ Universidade Federal de Santa Catarina, Programa de Pós-Graduação em Psicologia, Brasil

\author{
ART ICLE INFO \\ Article history: \\ Received 2018-07-03 \\ Accepted 2018-10-16 \\ Available online 2018-10-31 \\ *Autor correspondente: \\ E-mail:julia_psi_@hotmail.com
}

Palavras-chave: Reconhecimento. Vivências de prazer. Trabalho.

Keywords: Recognition; Experiences of pleasure; Work.

RESUMO. O reconhecimento no trabalho possui um importante papel enquanto fortalecedor da identidade $e$ protetor da saúde psíquica do trabalhador. Este estudo buscou identificar aspectos do trabalho de motoristas de transporte coletivo urbano relacionados ao reconhecimento. O referencial teórico utilizado foi a Psicodinâmica do Trabalho. Na pesquisa, de abordagem qualitativa e de caráter exploratório-descritivo, foram realizadas observações nos ambientes de trabalho utilizados pelos motoristas, tais como terminais de ônibus, linhas e nas dependências da empresa, e entrevistas coletivas, que foram submetidas a análise de conteúdo. Nos resultados percebeu-se que há uma diversidade de sentimentos que estão associados ao trabalho e a sua organização. As vivências de prazer mostraram-se associadas, principalmente, as diferentes formas de reconhecimento no trabalho. Ao mesmo tempo em que existe um autorreconhecimento e há um reconhecimento da empresa, de passageiros e da comunidade sobre a importância do trabalho do motorista. Esse aspecto gera satisfação e autoconfiança, possibilitando a construção de uma imagem e visão de si positiva enquanto profissionais.

ABSTRACT. Recognition in the work has an important role while strengthening of the identity and protector of the psychic health of the worker. This study aimed to identify the aspects of the work of urban collective transportation drivers related to the recognition. We used the "work psychodynamics" theory. In the research, with qualitative approach and descriptive-exploratory character, observations were made in work environments used by drivers, such as bus terminals, lines and company, and collective interviews, which were submitted to content analysis. In the results it was realized that there is a diversity of feelings that are associated with work and its organization. The experiences of pleasure have been associated, mainly, the different forms of recognition in the work. At the same time there is a self-recognition and there is a recognition of the company, the passengers and the community about the importance of the work of the driver. This aspect generates satisfaction and self-confidence that makes them construct a positive image and vision of themselves as professionals. 


\section{Introdução}

O trabalho pertence à história humana. Apesar dos diferentes objetivos e significações que lhe foram atribuídos ao longo dessa história, o trabalho ocupa um lugar central na vida do ser humano. É mais que apenas meio de subsistência, constrói laços sociais, é fonte de reconhecimento pessoal, com importância vital para a construção da subjetividade, sendo assim, é essencial para o equilíbrio e saúde psíquica dos indivíduos (ARAÚJO; PINHEIRO; GREGGIO, 2011; MAGNUS; MERLO, 2012).

O trabalho enquanto produtor de modos de subjetivação, que expressam as formas de viver em determinado período histórico, é um referencial para o desenvolvimento emocional, psíquico e cognitivo do indivíduo, além de contribuir para seu reconhecimento social. Em função disso, ocupa uma posição central no mundo contemporâneo (MERLO; DORNELLES; BOTTEGA; TRENTINI, 2012). O trabalho incide sobre as formas de organizar a sociedade, assim a estruturação dos pilares do trabalho é fundamental para assegurar a estabilidade dos meios de sustentação da mesma (MENDES; WÜNSCH, 2009).

O interesse pelo fenômeno trabalho converge em campos distintos do conhecimento, como objeto de pesquisa nas áreas da Saúde, Psicologia, Filosofia, Antropologia, Sociologia, Economia, Direito, entre outras. Diversas teorias buscam estudar e entender os conceitos que se interligam ou se contrapõem dependendo dos pressupostos teóricos adotados pelos pesquisadores. Este trabalho está situado no campo da Psicologia do Trabalho, especificamente, na Saúde do Trabalhador, que pressupõe uma interação entre alternativas de intervenção que considerem as diversas formas de determinação do processo saúde/doença dos trabalhadores (MENDES, J.M.R., 2007).

Dentre as perspectivas relacionadas ao estudo do trabalho, na Psicologia, optou-se por utilizar o enfoque proposto pela Psicodinâmica do trabalho. Para essa abordagem, o trabalho é um dos elementos essenciais na promoção do desenvolvimento psíquico, operando na construção da identidade em um espaço intersubjetivo: o ambiente de trabalho, com suas relações grupais e organizacionais (MAGNUS; MERLO, 2012). Dessa forma, o trabalho não é redutível a uma atividade de produção no mundo objetivo, ao colocar sempre a subjetividade do trabalhador à prova, fazendo com que saia transformada. Sendo assim, trabalhar é transformar a si mesmo, ou seja, uma possibilidade para a subjetividade se testar e se realizar. Com esse entendimento, trabalhar pressupõe uma atividade que permite ao sujeito produzir e revelar a si próprio, na dinâmica da realização do eu e da construção da identidade (FACAS; SILVA; ARAÚJO, 2013).

O 'trabalhar' implica os gestos, o saber-fazer, o engajamento do corpo, a mobilização da inteligência, a capacidade de refletir, de interpretar e de reagir às situações, bem como, o 
poder de sentir, de pensar e de inventar. A maior característica do trabalhar é que, mesmo que este seja bem concebido, a organização do trabalho seja rigorosa, as instruções e os procedimentos sejam claros, é muito difícil atingir a qualidade se as prescrições forem inteiramente respeitadas. No trabalho, as situações comuns são permeadas por acontecimentos inesperados e imprevistos (DEJOURS, 2004; 2008) e o trabalhador precisa agir e lidar com essas situações de modo eficaz.

Nessa medida, trabalhar significa, essencialmente, aplicar certas alterações na organização do trabalho prevista para se tornar executável. Assim, "a prescrição tem sempre que ser objeto de reajustamentos e mesmo de reinterpretações pelos trabalhadores, na situação de trabalho, para ser operacional” (DEJOURS, 1996, p. 165). A diferença entre o que se está prescrito pela organização do trabalho e a realidade concreta da situação é o que permite lidar com os imprevistos.

A partir da Psicodinâmica do trabalho é possível entender que o ato de "trabalhar" é o que preenche a lacuna entre o que está prescrito pela organização do trabalho e a realidade concreta da situação, ou seja, é aquilo que o sujeito acrescenta às prescrições para atingir aos objetivos impostos ou o que acrescenta de si mesmo para enfrentar o que não funciona quando se detém somente à execução das prescrições (DEJOURS, 2004). Os reflexos dessa relação, entre homem e o trabalho, representa um elemento contraditório para o ser humano, pois por um lado pode gerar prazer, realização, crescimento e desenvolvimento, por outro pode resultar em sofrimento e adoecimento (DEJOURS, 2004; BOTTEGA; MERLO, 2010).

Para Dejours (2007) a organização do trabalho exerce grande influência nas vivências de prazer e sofrimento relacionadas ao trabalho. Assim como o trabalho pode ser estruturante da identidade do trabalhador, ao favorecer o seu fortalecimento, pode, também ser desestruturante, ao enfraquecê-la. A resolução dessa questão centra-se no papel do reconhecimento como fortalecedor da identidade, sendo esse um protetor para a saúde psíquica do sujeito. O trabalho saudável respeita a identidade em sua construção plena dentro de um trabalho, cuja organização seja eticamente prescrita, respeitando potenciais e limites da condição humana, assim como conduz à criatividade e ao comprometimento com a realização de um trabalho de alta qualidade (DEJOURS, 2011; MENDES, A. M., 2007).

O reconhecimento, conforme descrito por Dejours (2007), é algo que o sujeito busca em relação ao seu fazer e não ao seu ser, é um julgamento sobre a sua relação com o real que se dá no trabalho. Dessa forma, o reconhecimento é algo que não pode ser prescrito na organização do trabalho, é uma retribuição simbólica advinda da contribuição dada pelo sujeito, pelo engajamento de sua subjetividade e inteligência (DEJOURS, 2005).

Frente a esse entendimento esta pesquisa objetivou identificar os aspectos do trabalho de motoristas de transporte coletivo urbano relacionados ao reconhecimento. Os trabalhadores do transporte coletivo urbano constituem uma categoria profissional em 
destaque, principalmente com a urbanização nas sociedades, não só por formarem um contingente numeroso de trabalhadores, expostos à condições de trabalho bastante particulares, mas também, pela responsabilidade coletiva de sua atividade (ALMEIDA, 2002; COSTA, 2006). O motorista é o profissional responsável pela integridade física de todos os passageiros (ALVES; PAULA, 2009; MACHADO; PORTO-MARTINS; BENEVIDESPEREIRA, 2014).

\section{Método}

Participaram do estudo onze motoristas de transporte coletivo urbana de uma empresa do interior do Rio Grande do Sul. Utilizou-se como critérios de seleção: não ter histórico de afastamento nos dois anos antecedentes a pesquisa e estar ao menos a um ano na empresa exercendo a função de motorista. Foram realizadas observações nos ambientes de trabalho utilizados pelos motoristas (empresa, terminais, linhas) e entrevistas coletivas.

A técnica da entrevista é um processo no qual os vínculos são estabelecidos, assim, à medida que o entrevistado fala, o entrevistador na sua escuta se envolve no discurso do entrevistado (MENDES, A.M., 2007). Quando isso é feito no coletivo, são formadas relações ricas de sentido e de criação entre os próprios entrevistados. Esse espaço possibilita a construção e reconstrução de modos de pensar e agir sobre o tema de discussão.

Os motoristas participantes foram divididos em dois grupos (Grupo 1 - seis motoristas e Grupo 2 - cinco motoristas) e as entrevistas coletivas ocorreram em dois encontros com cada grupo, sendo que cada encontro teve um tema norteador: (1) $O$ trabalho e a organização do trabalho e (2) Reconhecimento e sentidos do trabalho. Para a análise dos dados coletados com a entrevista coletiva, adotou-se a análise de conteúdo, um processo organizativo sistematizado e respaldado em Bardin (2011). A seguir é apresentada a tabela 1 com o perfil dos motoristas participantes das entrevistas coletivas. 
Tabela 1 - Perfil dos Motoristas participantes das entrevistas coletivas

\begin{tabular}{|c|c|c|c|c|c|c|}
\hline Participante & Idade & $\begin{array}{c}\text { Estado } \\
\text { civil }\end{array}$ & Escolaridade & $\begin{array}{c}\text { Tempo } \\
\text { Motorista } \\
\text { de TCU }\end{array}$ & $\begin{array}{c}\text { Tempo de } \\
\text { trabalho na } \\
\text { empresa }\end{array}$ & $\begin{array}{c}\text { Horário } \\
\text { de } \\
\text { trabalho }\end{array}$ \\
\hline Motorista A & 30 anos & Casado & $\begin{array}{l}\text { Ensino Médio } \\
\text { completo }\end{array}$ & 5 meses & 5 meses & $\mathrm{T} / \mathrm{N}$ \\
\hline Motorista B & 30 anos & Casado & $\begin{array}{l}\text { Ensino Médio } \\
\text { completo }\end{array}$ & $1 \mathrm{a} 2 \mathrm{~m}$ & 1 ano & $\mathrm{M} / \mathrm{T}$ \\
\hline Motorista C & 37 anos & Casado & $\begin{array}{l}\text { Ensino Médio } \\
\text { completo }\end{array}$ & $4 a 6 m$ & 5 anos & $\mathrm{M} / \mathrm{T}$ \\
\hline Motorista D & 37 anos & Casado & Superior Incompleto & $10 \mathrm{a} 5 \mathrm{~m}$ & $7 a 7 m$ & $\mathrm{M} / \mathrm{T}$ \\
\hline Motorista E & 38 anos & Casado & $\begin{array}{l}\text { Ensino Fundamental } \\
\text { Incompleto }\end{array}$ & $6 a 6 m$ & $13 a$ & $\mathrm{M} / \mathrm{T}$ \\
\hline Motorista F & 42 anos & Casado & $\begin{array}{l}\text { Ensino Fundamental } \\
\text { Incompleto }\end{array}$ & 3 meses & 3meses & $\mathrm{M} / \mathrm{T}$ \\
\hline Motorista G & 48 anos & Solteiro & $\begin{array}{l}\text { Ensino Fundamental } \\
\text { Incompleto }\end{array}$ & $18 a 2 m$ & $3 a 6 m$ & $\mathrm{M} / \mathrm{T}$ \\
\hline Motorista $\mathrm{H}$ & 49 anos & Casado & $\begin{array}{l}\text { Ensino Fundamental } \\
\text { Completo }\end{array}$ & 16anos & 16anos & $\mathrm{T} / \mathrm{N}$ \\
\hline Motorista I & 49 anos & Casado & $\begin{array}{c}\text { Ensino Fundamental } \\
\text { Completo }\end{array}$ & $17 \mathrm{a} 6 \mathrm{~m}$ & 23anos & $\mathrm{M} / \mathrm{T}$ \\
\hline Motorista J & 51 anos & Casado & $\begin{array}{l}\text { Ensino Fundamental } \\
\text { Completo }\end{array}$ & $12 \mathrm{a} 10 \mathrm{~m}$ & $12 \mathrm{a} 10 \mathrm{~m}$ & $\mathrm{MD} / \mathrm{M}$ \\
\hline Motorista L & 56 anos & Solteiro & $\begin{array}{l}\text { Ensino Fundamental } \\
\text { Incompleto }\end{array}$ & 26 anos & 26 anos & $\mathrm{M} / \mathrm{T}$ \\
\hline
\end{tabular}

Fonte: Os autores (2017).

A manutenção do sigilo e respeito às normativas sobre o manejo correto dos conteúdos de dimensões da vida humana foi mantida durante todo o estudo, a partir do cumprimento Resolução no 466, de 12 de dezembro de 2012, do Conselho Nacional de Saúde (BRASIL, 2013). Optou-se por apresentar alguns extratos de fala para ilustrar as categorias apresentadas no texto. Desta forma, foi escolhido por apresentar os motoristas com letras do alfabeto (A-L) no sentido de assegurar a confidencialidade dos mesmos. $O$ projeto foi aprovado no Comitê de Ética e Pesquisa da Universidade Federal de Santa Maria sob o número do parecer 245.199. 


\section{Resultados e Discussões}

\subsection{Características do trabalho do Motorista de Transporte Coletivo Urbano}

Em uma empresa de transporte coletivo urbano, o maior representativo de trabalhadores é de motoristas e cobradores, pertencentes ao setor operacional, juntamente com os conferentes e fiscais. Dos cerca de 500 trabalhadores da empresa pesquisada, em média 230 são motoristas, divididos em três terminais e em dois turnos de trabalho (manhã/tarde e tarde/noite). A jornada de trabalho é de 7 horas e 20 minutos ao dia, com intervalo entre 1 e 4 horas e, um dia de folga semanal.

Além do setor operacional, a empresa conta com um setor administrativo e um setor de manutenção, sendo que este é responsável por manter os veículos em bom estado para sua utilização nas linhas e na produção do serviço de transporte. Na empresa, o contato com esses setores e com a direção da empresa é pouco frequente. "É que um sistema um pouco diferente, agente quando tem algum problema agente faz a ficha no terminal e o fiscal se encarrega de mandar o ônibus para a oficina (MOTORISTA J)", "Quando é preciso, o acesso também aos setores da empresa é fácil... aos gerentes é fácil, a própria direção se estiver disponível é fácil (MOTORISTA E)" e,

\footnotetext{
Quando acontece alguma coisa no caminho que tu consiga trazer o ônibus até aqui (garagem/manutenção). Daí tu chega aqui e fala com o chefe da oficina, olha aconteceu tal coisa. Mas fora isso o teu contato é bem restrito, praticamente não tem contato. $\mathrm{E}$ com a parte administrativa muito menos [...] Nosso contato maior é com o Departamento de Pessoal, para pegar contracheque, assinar férias... (MOTORISTA B)
}

Embora haja pouco contato, nos trechos citados anteriormente se torna claro que há possibilidade de acesso, porém ele ocorre em situações específicas. Esse aspecto se relaciona ao fato de a empresa estar dividida em terminais localizados em pontos diferentes da cidade e também pelas características do trabalho do motorista, que acontece principalmente fora dos portões da empresa.

A atividade profissional de motorista de transporte coletivo possui peculiaridades que se tornam um diferencial em relação às demais profissões, pois estes trabalhadores estão expostos a diferentes fatores prejudiciais à saúde, tais como: ruídos, gases tóxicos, trânsito intenso, vandalismo, violência, fatores resultantes da relação cliente-serviço, relacionamentos com colegas e chefias, veículos com condições inadequadas quanto à ergonomia. A organização do trabalho nesta empresa de transporte coletivo ocorre em dois locais distintos, ou seja, na garagem e terminais e nas linhas. A garagem e/ou terminal é 
denominação cotidiana dos trabalhadores para o local do pátio de estacionamento dos ônibus, quando esses não estão operando.

Percebe-se também que o trabalho do motorista de transporte coletivo é realizado em um ambiente de trabalho diferenciado dos demais trabalhadores, ou seja, nas ruas da cidade, em um ambiente público. O motorista de transporte urbano não possui um local restrito e bem definido para realizar suas tarefas, ao contrário, trabalha fora dos portões da empresa, estando sujeito a intempéries como o clima, as condições de tráfego e do trajeto das vias. Além disso, os motoristas de transporte urbano de passageiros mostram-se cotidianamente pressionados pelas exigências relacionadas ao tempo de deslocamento, aos cuidados com o veículo e à responsabilidade pelas vidas dos passageiros. $O$ fato da jornada de trabalho desses trabalhadores ocorrer no trânsito é peculiar, pois eles permanecem a maior parte da jornada de trabalho fora dos limites convencionais de uma empresa. Esse aspecto pode implicar na aplicação de normas rígidas de fiscalização no que diz respeito ao cumprimento de horários, cuidados com o veículo (dado que são responsáveis por qualquer dano ao mesmo), diversidade dos comportamentos dos passageiros, além da responsabilidade que têm sobre a vida das pessoas que conduzem durante seu expediente (BATTISTON; CRUZ; HOFFMANN, 2006).

No trabalho dos motoristas, os reflexos da organização do trabalho ficam bem caracterizados por regulamentações, além da exigência do cumprimento do quadro de horários, colocado em prática pela escala confeccionada pela empresa. Os motoristas de cada linha têm o tempo exato para percorrer determinado itinerário, pois o ritmo do andamento do trabalho de cada dupla (motorista e cobrador) está ligado ao trabalho das outras linhas, em uma relação de interdependência. As formas de controle se dão pelos trabalhadores que ocupam os cargos de chefia, os quais são encarregados de fiscalizar as linhas e verificar o andamento do serviço, o cumprimento de horários, das normas da empresa e alguma pendência existente (CRUZ, 1998).

Dessa forma, a organização do trabalho na linha e terminais se dá a partir dos conferentes e, principalmente, de fiscais que ficam nos pontos de controle e tem a função de acompanhar e registrar o fluxo de veículos, a movimentação de pessoal de operação, avisando à garagem/empresa quaisquer alterações significativas no serviço. O fiscal também realiza o trabalho de controle e verificação dos modos e condições de operação das linhas durante a circulação dos veículos. Os trechos de falas a seguir mostram essa relação com os fiscais e os terminais e/ou garagem: "Aconteceu comigo, eu tinha dois meses de empresa e uma mulher 'bateu' em mim, mas ela quis me culpar, o fiscal que foi lá (no local do acidente) viu que eu não tinha culpa aí ele viu tirou fotos e tudo [...] (MOTORISTA A)",

Tu tens chefias imediatas [...] lá no terminal, quem manda, coordena e da às diretrizes é o fiscal. Agora se tu tiver aqui em baixo (garagem/empresa), daí talvez não seja o fiscal, ele vai encaminhar para o gerente operacional. Mas 
essa relação é assim, se tu é motorista então tem que trabalhar como motorista, se ele precisar falar contigo ele vem e te fala, cada um trabalha na sua função (MOTORISTA E)

[explica uma situação de erro da placa do itinerário] Daí o cobrador falou quando eu estava parado na sinaleira, "abre a porta que eu vou dar uma olhadinha, para conferir de novo". Então os fiscais estavam na parada daí viram e já me 'canetiaram', porque eu não podia andar com a porta aberta [...] (MOTORISTA C)

O motorista cumpre sua jornada de trabalho, operando o veículo no itinerário e horários estabelecidos, normalmente junto com o cobrador que recolhe a tarifa (CRUZ, 1998; PRANGE, 2011). Durante a realização do trabalho nas linhas, a equipe, formada pelo motorista e o cobrador, precisa estabelecer formas de trabalho que garantam a realização do percurso determinado com segurança e qualidade. Cabe aos dois, em consenso, construir um modo de trabalho que leve em consideração as necessidades de ambos. Nesta relação, segundo os motoristas, destaca-se o auxílio e a confiança adquirida no cobrador, conforme descrito nos seguintes trechos "O cobrador é o braço direito do motorista [...] um usuário correndo, uma velhinha que vem por baixo, tem muito lugar que pega a parte cega do espelho [...] O cobrador é fundamental (MOTORISTA F)", "Só de olha ele sabe o que é que a gente quer dizer pra ele [...] Para manobrar ajuda e muito [...] tu tem que confiar (MOTORISTA D)" e "O cobrador é bom quando ele te ajuda a dirigir, 'eu cuido aqui e ele lá, olha cuidado que vem um carro ali'... sem cobrador não dá pra dirigir (MOTORISTA C)".

\subsection{O reconhecimento para os motoristas}

Com a análise das falas dos motoristas participantes da pesquisa, pode-se identificar elementos importantes associados ao entendimento de reconhecimento para os profissionais. Esse aspecto foi principalmente relacionado à vivências positivas no trabalho, que geram prazer, satisfação e realização. Essas vivências promovem um sentimento de bem-estar geral, que estimula os vínculos de envolvimento com 0 trabalho e comprometimento com a organização. A satisfação no trabalho apareceu na fala da maioria dos motoristas, associada, principalmente, ao fato de realizarem um trabalho que gostam, de terem um bom relacionamento com os passageiros e conseguirem cumprir a jornada de trabalho conforme o planejado: "A satisfação de levantar e trabalhar... de alegria...E de fazer o teu serviço, o que tu gosta de fazer, o que tu sabe que faz bem (MOTORISTA A)", "A satisfação por estar desenvolvendo um trabalho que gosto [...] Quando tu termina a tua jornada, tranquilo, aquela sensação de dever cumprido, de ter alcançado os objetivos do dia [...] (MOTORISTA E)"

Pra mim a satisfação é meio geral. Até com o próprio passageiro a gente tem um carisma com muitos, isso é bom, como isso levanta a moral [...] 
Assim quando a gente termina a jornada, a gente dá: 'graças a Deus deu tudo ok', isso aí me alivia, [...] (MOTORISTA J).

Tentar fazer bem feito, sempre tentar fazer bem feito. Sair e chegar bem é um prazer que a gente tem, o ruim é quando a gente chega aqui [garagem da empresa] e quando vai sair para ir embora dizem: 'fulano ligou assim e reclamou disso', daí dá um desanimo que é uma coisa triste. [...] (MOTORISTA H)

A satisfação e o envolvimento no trabalho têm sido frequentemente considerados como vínculo afetivo positivo com o trabalho, envolvendo aspectos específicos como relacionamento com a chefia e colegas de trabalho, salário, oportunidades de crescimento e política de gestão da organização, entre outros (SIQUEIRA; PADOVAM, 2008). Embora as vivências positivas, atribuídas ao reconhecimento e aos elogios com relação ao desenvolvimento do trabalho, repercutem em um bom vínculo com o trabalho, essas atitudes, conforme o discurso dos motoristas, não são práticas constantes na organização e dos passageiros. Apesar disso, quando acontecem trazem satisfação, orgulho e motivação, elevando a autoestima e provocando uma sensação de bem-estar na relação com o trabalho: "Quer ver uma satisfação boa: 'fulano ligou de lá e pediu para assinar um elogio pra ti porque está sempre no horário' [...] a gente fica faceiro (MOTORISTA F)",

Tem uns que reconhecem! Mas outros nem tanto. Eles [passageiros] mesmos falam da importância, a gente vê eles falando... Mas é a minoria... A gente passa quase 24 horas na linha. Quando a gente não está eles perguntam... (MOTORISTA I)

Já tive elogios sim... me chamou a atenção uma vez que socorri uma passageira que passou mal no ônibus [...]. Deixamos ela no PA [pronto atendimento], daí uma passageira que estava no ônibus entrou em contato com o colunista do Jornal $X$ e me fez um elogiou pelo jornal, pela atitude, pelo pronto-atendimento com o passageiro. Me chamou bastante atenção porque a passageira não era parente dela, não era nada, e mesmo assim ela encontrou um meio de me elogiar, as palavras do jornalista também foram bem interessantes [...] (MOTORISTA E)

Nesta última fala é possível identificar que o reconhecimento também aparece quando há um desempenho bom ou diferenciado do motorista na função. O que foi descrito anteriormente pelo Motorista E. revela a capacidade do profissional de lidar com situações que são imprevistas, aspecto relacionado diretamente com o ato de trabalhar, conforme a abordagem teórica utilizada nesse estudo. Dessa forma, outros exemplos que indicam o fato de lidar com aspectos fora do prescrito pela organização do trabalho são quando os motoristas conseguem evitar um acidente ou realizam uma manobra difícil que é reconhecida pelos passageiros. O reconhecimento por parte dos passageiros é referido nos seguintes trechos: "[...] e para o usuário também, porque muitos usuários já estão acostumados com esse [motorista] aqui com aquele ali, imagina 'Oh fulano, com é que tu 
está?' vai acostumando, não é? (MOTORISTA F)", "A gente passa quase 24 horas na linha. Quando a gente não está eles (passageiros) perguntam [...] (MOTORISTA I)" e

Logo que eu entrei [...] estava vindo tranquilo, calmo, estava com o ônibus cheio e eu estava bem devagar vindo na faixa mesmo e aí um senhor desceu e disse "tu é novo, não é?" eu disse sou! "ah continua assim, tu foi muito bem!" e até mexi com ele. Eu agradeci e disse pra ele: "se der para o senhor dar uma ligadinha lá pra empresa, ia ser melhor" (MOTORISTA A)

Esse reconhecimento torna-se ainda mais valorizado pelos trabalhadores, pois eles atribuem características a si e ao seu trabalho que os diferenciam dos demais motoristas (que não são profissionais do transporte coletivo urbano). Em vários momentos eles se referiam ao ser profissional, ter responsabilidade, agir com segurança, ter autocontrole, muita atenção, capacidade de adaptação como fundamentais para o exercício da profissão e como diferenciais frente aos demais motoristas: "[...] se não é o motorista de ônibus ali, todo dia dava batida [...] (MOTORISTA A)", "Profissionalismo, [...] ser um bom motorista, responsável, atender bem as pessoas porque faz parte do nosso trabalho (MOTORISTA G)"

Tu é motorista, vai dirigir o ônibus que tem, no horário que tiver. Para ser um bom profissional precisa se adequar a aquele veículo. [...] Não é qualquer pessoa que vai lá e pega quatro ônibus diferentes e vai conseguir trabalhar (MOTORISTA E)

Essas características, quando associadas, parecem criar uma autoimagem do motorista e de sua importância bastante positivas, que os protege dos diferentes tipos de agressões a que estão expostos. Dessa forma, pode minimizar as vivências negativas que trazem sofrimento, tornando-se uma estratégia de defesa coletiva, compartilhada pela maioria e que fortalece o grupo no enfrentamento das situações.

As falas acima se mostram carregadas de realização e confiança acerca da importância do bom desempenho da função de motorista. O reconhecimento torna-se essencial para identidade, e assume duas formas: a de que fazemos parte de algo maior e a de que somos seres singulares. Com o trabalho central na vida do indivíduo, o pertencimento a um grupo, torna-se crucial. Não existe uma separação entre mundo objetivo do emprego e o mundo subjetivo do reconhecimento da existência do indivíduo (FREITAS; HELOANI; BARRETO, 2008). O ser profissional, em alguns momentos, refere-se, para esses motoristas, à capacidade de adaptação às mudanças necessárias nas condições de trabalho como, por exemplo, a necessidade de mudança de veículo quando é realizado uma manutenção preventiva no ônibus que já se está acostumado a dirigir. 
Tu és motorista e vai dirigir o ônibus que tem, no horário que tiver. Pra ti ser um bom profissional, tu precisa se adequar aquele veículo. Quem é fixo, as vezes, muda de ônibus e tem que se adaptar também A gente chega lá (terminal) e eles dizem: hoje tu pega tal (ônibus) que o outro foi fazer tal coisa...Tu vais ter que pegar o ônibus e vais ter que trabalhar, é pertinente da função do motorista, vai lá pega o ônibus e vai embora. Claro que o ideal é tu pegar sempre o mesmo, mas nem sempre isso é possível... se pega quatro ônibus diferentes, são quatro embreagens diferentes, são quatro freios diferentes, são quatro direções diferentes, tem que ter habilidade. Não é qualquer pessoa que vai lá e pega quatro ônibus diferentes e vai conseguir trabalhar (MOTORISTA E)

O trabalho ocupa um lugar muito importante na luta contra o adoecimento, pois ele constrói o reconhecimento social para o trabalhador. Dessa forma o reconhecimento é fundamental ao trabalhador, dando sentido ao sofrimento, pois, quando o trabalho é reconhecido, o julgamento ocorre sobre o trabalho (BOTTEGA; MERLO, 2010). Assim, na relação trabalho e indivíduo, o reconhecimento pelo outro, adquire importância na dinâmica identidade e prazer. Mas para que haja o reconhecimento, é necessária uma reconstrução dos julgamentos acerca do trabalho realizado, isto é, será destinado ao trabalho feito, e não à pessoa enquanto sujeito. O que não quer dizer que não interferirá nas expectativas subjetivas do profissional, pois esta retribuição simbólica reflete na realização de si mesmo (CASTRO; MERLO, 2011).

Destaca-se ainda, que há um reconhecimento da importância do próprio trabalho para o funcionamento da empresa e da cidade como um todo. Os motoristas reconhecem que fazem parte de um serviço que atende a população urbana e que são necessários para o funcionamento da cidade. Esse reconhecimento aparece através das seguintes falas: "Se tivessem paralisações, a cidade ia parar só porque não tinha ônibus funcionando (MOTORISTA L)", "Se a gente não vir trabalhar os ônibus não vão sair. A empresa não vai ter não é? A empresa sem motorista não vai funcionar (MOTORISTA C)",

Eu acho muito importante, é o nosso trabalho que, praticamente, conduz o funcionamento da cidade, por que se não tem ônibus, se não tem motorista para pegar o ônibus aqui, várias pessoas não vão conseguir chegar ao seu trabalho por que não tem outra forma [...] (MOTORISTA E)

A empresa precisa de dois funcionários para um horário para carrega até 80, 90 passageiros numa volta. Então é dois (trabalhadores) que a empresa precisa. E quantos precisam desses dois? (se referindo à população atendida) [...] (MOTORISTA J)

O autorreconhecimento é reforçado pelos dirigentes e encarregados da empresa que, em reuniões, expressam a importância do trabalho do motorista e do cobrador de ônibus tanto para o funcionamento da empresa, quanto para a comunidade. Com isso, percebe-se que a empresa também utiliza da valorização e do reconhecimento como uma estratégia de responsabilização e engajamento dos motoristas no seu trabalho: "[...] é 
fundamental, é importante, nós somos os caras, é a visão que a empresa tem, que já foi me dito por um fiscal, A empresa precisa de uma dupla para transportar quantos passageiros?! [...] (MOTORISTA J)" e,

[...] foi falado em uma reunião: qual é a utilidade do motorista e do cobrador? A utilidade do motorista e do cobrador é fazer a empresa andar para frente, carregar o usuário, transportar pessoas! Por exemplo: falta motorista e cobrador e tem um fiscal: o ônibus sai? Não! Tem dois fiscais, três fiscais o ônibus vai sair? Não! Vai ter que ter o motorista e o cobrador, não sai se não tiver o motorista e o cobrador, então [...] o motorista e o cobrador para a comunidade é fundamental (MOTORISTA F)

Assim o reconhecimento, enfatiza Mendes A.M. (2007), ao mesmo tempo em que possibilita o fortalecimento da estruturação psíquica e da saúde, através do reconhecimento daquele que trabalha, do seu esforço e investimento na tarefa, também pode ser uma estratégia da organização para capturar os trabalhadores na armadilha da dominação. A organização do trabalho, na promessa de utilizar o trabalho como forma de auto realização, pode levar o trabalhador a exaustão e a outras psicopatologias associadas a seu trabalho.

As falas apresentadas trazem a importância do reconhecimento tanto vertical, quanto horizontal. Para Dejours (2007) estes são condições importantes no processo de mobilização subjetiva da inteligência e da personalidade no trabalho e se dá por duas vias de julgamento: o julgamento de utilidade e o julgamento de "beleza". O primeiro, diz respeito à utilidade técnica, social ou econômica dada à atividade singular desempenhada pelos trabalhadores, proferido pelo outro, na linha vertical (chefes, subordinados e clientes). 0 julgamento de "beleza" por outro lado, é aquele efetuado horizontalmente, pelos pares e comunidade de pertença, ou seja, aqueles que, situados na mesma faixa hierárquica e compartilhando o mesmo ofício, estão em condições de avaliar a singularidade e a "beleza" do trabalho executado.

Dessa forma, percebe-se que ao mesmo tempo em que existe um autorreconhecimento e um reconhecimento da empresa, de passageiros e da comunidade sobre a importância do trabalho do motorista gerando satisfação e autoconfiança que faz com que construam uma imagem e visão de si positiva enquanto profissionais. Há um efeito negativo dessa construção, que é um excesso de cobrança, exigência e controle que geram uma tensão e pressão por bom desempenho.

\section{Considerações finais}

Este estudo traz reflexões a partir da análise das informações propostas nesta pesquisa. A organização do trabalho do motorista de transporte coletivo urbano possui 
diferenciais significativos quando comparada a de outras categorias. Além do ambiente de trabalho que possui inúmeras características advindas da necessidade de trabalhar fora dos portões da empresa, estando sujeito a aspectos que interferem em sua segurança física, as exigências dos usuários, as condições do tempo, as condições de tráfego e do trajeto das vias, possuem como os demais trabalhadores pressões internas como condições de saúde (física e psíquica), condições ergonômicas, satisfação com o trabalho, relacionamento decorrentes do trabalho (colegas, hierarquia), dentre outras.

A forma pela qual o trabalho está organizado atinge a subjetividade dos seus trabalhadores e, para os motoristas de transporte coletivo urbano estudados, podem levar a diversos tipos de vivências, dentre elas de reconhecimento e prazer. As vivências positivas, principalmente de satisfação, geram prazer e realização ao trabalho desses profissionais, e estão associadas, principalmente, com o fato de realizarem um trabalho que gostam, de terem um bom relacionamento com os passageiros e conseguirem cumprir a jornada conforme o esperado. Através das falas, é possível inferir que o reconhecimento e aos elogios trazem satisfação, orgulho e motivação, elevando a autoestima e provocando uma sensação de bem-estar na relação com o trabalho.

Os relacionamentos estabelecidos com os diferentes atores envolvidos no desempenho do trabalho do motorista, embora possam trazer vivências ambíguas, se mostraram fundamentais para a autoestima, a valorização e o reconhecimento. Esse último aspecto quando relacionado a importância do trabalho para a empresa, para a população e para a cidade carrega-se de um tom polifônico, ou seja, os discursos partem desses diferentes locais e se misturam ao próprio posicionamento do motorista. Esse aspecto ao mesmo tempo em que gera prazer, autoconfiança, otimismo e satisfação no trabalho, serve a dominação da empresa, suscitando responsabilização que muitas vezes exige um grande autocontrole e atenção ao trabalho. Isso repercute em um aumento da carga psíquica de trabalho que precisa encontrar outros meios para a sua descarga.

Os dados apresentados através dos relatos dos motoristas participantes, embasados pelo entendimento da Psicodinâmica do Trabalho, podem ser valiosos instrumentos a serem explorados, para que se possa criar estratégias de transformações da organização do trabalho, gerando benefícios para a saúde desses trabalhadores. Além disso, criou-se um espaço de fala e escuta que se mostra como fundamental para que os trabalhadores acreditem na possibilidade de participar e contribuir para essas mudanças. 


\section{Referências}

ALMEIDA, Nemésio Dario Vieira De. Contemporaneidade $\mathbf{X}$ trânsito: reflexão psicossocial do trabalho dos motoristas de coletivo urbano. Psicologia: Ciência e profissão, v. 22, n. 3, p. 66-69, 2002.

ALVES, Camila Renata da Silva, PAULA, Patrícia Pinto de. Violência no trabalho: possíveis relações entre assaltos e TEPT em rodoviários de uma empresa de transporte coletivo. Cadernos Psicologia Social do Trabalho, v. 12, n.1, p. 35-46, 2009.

ARAÚJO, José Newton Garcia; PINHEIRO, Tarcísio Márcio Magalhães; GREGGIO, Maria Regina. Notas sobre o adoecimento mental em trabalhadores rurais. In: ZANELLI, José Carlos, SILVA, Narbal, TOLFO, Suzana da Rosa (Orgs.), Processos psicossociais nas organizações e no trabalho. São Paulo: Casa do Psicólogo, 2011.

BARDIN, Laurence. Análise de Conteúdo. 7. ed. rev. e amp. São Paulo: Edições 70, 2011. BATTISTON, Márcia, CRUZ, Roberto Moraes, HOFFMANN, Maria Helena. Condições de trabalho e saúde de motoristas de transporte coletivo urbano. Estudos de Psicologia. v. 11, n. 3, p. 333-343, 2006.

BOTTEGA, Carla Garcia, MERLO, Álvaro Roberto Crespo. Prazer e sofrimento no trabalho dos educadores sociais com adolescentes em situação de rua. Cadernos de psicologia social do trabalho. v. 13, n. 2, p. 259-275, 2010.

BRASIL. Resolução n 466, 12 de dezembro de 2012. Dispõe sobre as diretrizes e as normas regulamentadoras de pesquisa envolvendo seres humanos. Conselho Nacional de Saúde. $\quad$ Brasília, $2013 . \quad$ Disponível em:< http://conselho.saude.gov.br/resolucoes/2012/Reso466.pdf >. Acesso em: 25 ago. 2013. CASTRO, Thiele da Costa Muller, MERLO, Álvaro Roberto Crespo. Reconhecimento e saúde mental na atividade de segurança pública. Psico, v. 42, n. 4, p. 474-480, 2011 COSTA, Elisangela Azevedo Viana Gomes da. Estudo dos constrangimentos físicos e mentais sofridos pelos motoristas de ônibus urbano da cidade do Rio de Janeiro. Rio de Janeiro, Rio de Janeiro, 2006. Dissertação (mestrado em Design) - Pontifícia Universidade Católica do Rio de Janeiro.

CRUZ, Marcus Vinicius Gonçalves da. Produção do serviço de transporte público urbano por ônibus: aspectos da organização do trabalho. Revista de Administração Contemporânea, v. 2, n. 3, p. 45-65, 1998.

DEJOURS, Christophe. Uma nova visão do sofrimento humanos nas organizações. In: TORRES, Ofélia de Lanna Sette (Org.). 0 indivíduo na organização: dimensões esquecidas. 3. ed. São Paulo: Atlas, 1996.

DEJOURS, Christophe. Subjetividade, trabalho e ação. Revista Produção, v. 14, n. 3, p. 27-34, dez. 2004. 
DEJOURS, Christophe. O fator humano. 5. ed. Rio de Janeiro: FGV, 2005.

DEJOURS, Christophe. A banalização da Injustiça Social. 7. ed. Rio de Janeiro: FGV, 2007.

DEJOURS, Christophe. Cadernos de TTO, 2: A avaliação do trabalho submetida à prova do real. São Paulo: Blucher, 2008.

DEJOURS, Christophe. Psicodinâmica do Trabalho: contribuições da Escola Dejouriana à análise da relação prazer, sofrimento e trabalho. 1.ed. 12 reimp. São Paulo: Atlas, 2011.

FACAS, Emílio Peres, SILVA, Laiury Maiara da, ARAÚJO, Maria Aparecida Souza. Trabalhar. In: VIEIRA, Fernando de Oliveira (org.) Dicionário crítico de gestão e psicodinâmica do trabalho. Curitiba: Juruá, 2013.

FREITAS, Maria Ester de, HELOANI, Roberto, BARRETO, Margarida. Assédio moral no trabalho. São Paulo: Cengage Learning, 2008.

MACHADO, Pedro Guilherme Basso, PORTO-MARTINS, Paulo Cesar, BENEVIDESPEREIRA, Ana Maria T. Engagement no trabalho em profissionais de uma empresa de transporte público urbano. Psicologia Argumento, v. 32, n.79, p. 175-185, 2014.

MAGNUS, Cláudia de Negreiros, MERLO, Álvaro Roberto Crespo. Sofrimento-Prazer: Dinâmica do Trabalho de Profissionais de Saúde Mental de um Hospital Psiquiátrico Público. PSICO, v. 43, n. 2, p. 185-192, 2012.

MENDES, Ana Magnólia (org.). Psicodinâmica do trabalho: teoria, método e pesquisas. São Paulo: Casa do Psicólogo, 2007.

MENDES, Jussara Maria Rosa. 0 acidente e a morte no trabalho: o verso e o anverso de uma história e a construção social de sua invisibilidade. In: CODO, Wanderley (org). Saúde mental e trabalho: Leituras. 3.ed. Rio de Janeiro: Ed Vozes. 2007.

MENDES, Jussara Maria Rosa, WÜNSCH, Dolores Sanches. Trabalho, classe operária e proteção social: reflexões e inquietações. Revista Katálysis. v. 12 n. 2 p. 241-248, 2009. MERLO, Álvaro Roberto Crespo, DORNELLES, Rogério Alexandre Nedir, BOTTEGA, Carla Garcia, TRENTINI, Laís. O trabalho e a saúde dos oficiais de Justiça Federal de Porto Alegre. Cadernos de psicologia social do trabalho, v. 15, n. 1, p. 101-113, 2012.

SIQUEIRA, Mirlene Maria Matias; PADOVAM, Valquíria Aparecida Rossi. Bases teóricas do bem-estar subjetivo, bem-estar psicológico e bem-estar no trabalho. Revista Psicologia: Teoria e Pesquisa, v. 24, n. 2, p. 201-209, 2008.

PRANGE, Ana Paula Lobão. “Quem dá mais, cobra mais!” Uma análise das normas antecedentes do ofício de motorista de ônibus em um contexto específico. Estudos e Pesquisas em Psicologia, v. 11, n. 2, p. 551-565, 2011. 